ANL/MSD/CP- - 86757

$$
\text { CONF-951/55--121 }
$$

\title{
IN-SITU HVEM STUDIES OF RADIATION-INDUCED SEGREGATION IN Ni-Al ALLOYS DURING SIMULTANEOUS IRRADIATION WITH ELECTRONS AND IONS
}

\author{
M. J. Giacobbe $a, b$, N. Q. Lam $a$, P. R. Okamoto $a$, and J. F. Stubbins $b$ \\ a Argonne National Laboratory \\ Materials Science Division \\ Argonne, IL 60439 \\ $b$ University of Mlinois \\ Department of Nuclear Engineering \\ Urbana, IL 61801
}

\section{May 1996}

The submitted manuscript has been authored
by a contractor of the U.S. Government
under contract No. W-31-109-ENG-38.
Accordingly, the U.S. Government retains a
nonexclusive, royalty-free IIcense to publish
or reproduce the published form of this
contribution, or allow others to do so, for
U.S. Government purposes.

Manuscript presented at Materials Research Society Fall Meeting, Boston, MA, November 27 - December 1, 1995.

*Work supported by the U.S. Department of Energy, Basic Energy SciencesMaterials Sciences, under contract No. W-31-109-Eng-38. 


\title{
IN-SITU HVEM STUDIES OF RADIATION-INDUCED SEGREGATION IN Ni-Al ALLOYS DURING SIMULTANEOUS IRRADIATION WITH ELECTRONS AND IONS
}

\author{
M. J. Giacobbe a,b, N.Q. Lam a, P.R. Okamoto a, J.F. Stubbins b \\ a Argonne National Laboratory, Materials Science Division, Argonne, $\mathbb{L}$ \\ b University of Illinois at Urbana-Champaign, Department of Nuclear Engineering, Urbana, $\mathbb{L}$
}

\begin{abstract}
The effects of 75-keV Ne${ }^{+}$and $300-\mathrm{keV} \mathrm{Ni}^{+}$bombardment on electron radiation-induced segregation (RIS) in a Ni-9at.\%Al alloy were investigated in-situ using the HVEM (high voltage electron microscope)/Tandem accelerator facility at Argonne National Laboratory. The radial component of defect fluxes generated by a highly-focused $900-\mathrm{keV}$ electron beam was used to induce segregation of $\mathrm{Al}$ atoms towards the center of the electron irradiated area via the inverseKirkendall effect. The radial segregation rate was monitored by measuring the increase in the diameter of the $\mathrm{Al}$ enriched zone within which $\gamma^{\prime}-\mathrm{Ni}_{3} \mathrm{Al}$ precipitates form during irradiation. Both dual electron-ion and pre-implanted ion-electron irradiations were performed in an attempt to separate the contributions of energetic displacement cascades and implanted ions acting as defect trapping sites to RIS suppression. It was found that $75-\mathrm{keV} \mathrm{Ne}{ }^{+}$implantation has a retarding effect on RIS.
\end{abstract}

\section{INTRODUCTION}

Radiation-induced segregation (RIS) of the chemical constituents of an alloy is a wellknown phenomenon that occurs because defect annihilation at sinks induce defect fluxes that tend to couple preferentially to atom fluxes of a particular alloy component $[1,2]$. The preferential coupling can arise via the inverse-Kirkendall effect or via defect-solute interactions that result in the formation of mobile solute-defect complexes [1-3]. RIS processes driven by radial gradients in the concentration of point defects generated by highly-focused electron beams have been used to induce precipitation of $\gamma^{\prime}-\mathrm{Ni}_{3} \mathrm{Al}$ and $\gamma^{\prime}-\mathrm{Ni}_{3} \mathrm{Si}$ phases in undersaturated $\mathrm{Ni}-\mathrm{Al}$ and $\mathrm{Ni}$-Si solid-solutions respectively, and to cause a redistribution of these phases in initially two phase alloys [4-7]. As shown by Lam and Okamoto [5-8], the redistribution of the $\gamma^{\prime}$-phase provides a direct measure of electron beam-induced solute segregation rate. In the present work, we show that the electron beam driven segregation rate in a Ni-9at.\% Al alloy can be altered by irradiating the sample simultaneously with ions or by pre-implanting the sample with ions prior to electron irradiation.

\section{EXPERIMENTAL PROCEDURE}

In-situ electron-ion dual irradiations were carried out at the Argonne HVEM/Tandem accelerator facility. All irradiations were performed at $550^{\circ} \mathrm{C}$ with $900-\mathrm{keV}$ electrons and either $75-\mathrm{keV} \mathrm{Ne} e^{+}$or $300 \mathrm{keV} \mathrm{Ni}{ }^{+}$ions. Ne was selected to study the effect of implanted gas atoms on segregation kinetics, while $\mathrm{Ni}$ was chosen to study the effect of cascade damage. TRIM calculations indicated the $99 \%$ of the $300-\mathrm{keV} \mathrm{Ni}^{+}$ions and $100 \%$ of the $75-\mathrm{keV} \mathrm{Ne}^{+}$ions are stopped within a distance of $180 \mathrm{~nm}$ from the top foil surface. 
The defect distribution produced in a thin film by a focused electron beam is shown schematically in Fig. 1. Here $D_{0}$ is effective beam diameter defined by $I_{T}=I_{0}\left(\pi D_{0} / 2\right)^{2}$ where $I_{T}$

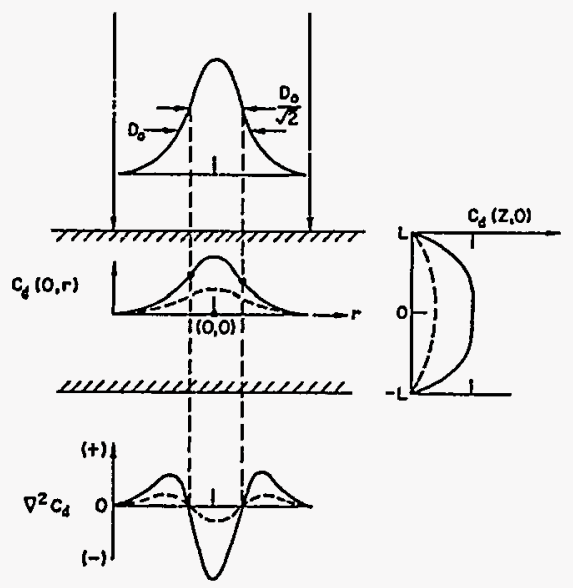

Figure 1. Top to bottom: electron beam profile, radial and axial defect production profile, and radial defect divergence. The defect gradients determine the direction and magnitude of the defect flux, while the defect divergence determines the local rate of solute accumulation or depletion [6-8]. was assumed to be bi-Gaussian and of the form $I(x, y)=I_{0} \exp \left\{-\left(x / a_{0}\right)^{2}-\left(y / b_{0}\right)^{2}\right\}$ where $a_{0}=$ $\sqrt{2} \sigma_{\mathrm{a}}$ and $\mathrm{b}_{\mathrm{o}}=\sqrt{2} \sigma_{\mathrm{b}}$ ( $\sigma^{\prime}$ s are the standard deviation of the beam profile along the major and minor axes). The dimensions of the precipitate zones along their major and minor axes were taken as $a / a_{0}$ and $b / b_{0}$ respectively. Normalizing measurements with respect to beam dimensions allows both $a / a_{0}$ and $b / b_{0}$ to be shown on the same scale.

\section{RESULTS}

Results are summarized in Figures 2, 3, 4, and 5. Figures 2 and 3 show the $\gamma^{\prime}$ growth under electron only, dual electron-ion, and electron only after ion implantation irradiation conditions. In both the dual and pre-implanted cases, a $\gamma^{\prime}$ zone was seeded with a 900-keV electron irradiation before the samples were subjected to any ion bombardment as seen in Figures $4 \mathrm{~b}-\mathrm{c}, \mathrm{t}=720 \mathrm{~s}$, and $5 \mathrm{~b}, \mathrm{t}=420 \mathrm{~s}$. In all cases, the focused electron beam, slightly elliptical in geometry, ranges from $1.0-1.2 \mu \mathrm{m}$ on the major axis and $0.80-0.95 \mu \mathrm{m}$ on the minor axis (the beam dimensions are $a_{0}$ and $b_{0}$, defined in the previous section). All beam dimension calculations are dependent on the assumption that the electron beam is bi-Gaussian in nature.

The effects of 75-keV Ne+ implantation on RIS are demonstrated in Figure 2. During the dual electron-ion irradiation, the growth of the precipitate zone was somewhat suppressed (micrographs in Figure 4b). After ion implantation to $10^{15} \mathrm{ion} / \mathrm{cm}^{2}$, the growth of the precipitate zone experienced greater suppression than during dual irradiation (micrographs in Figure 4c). The effects of $300-\mathrm{keV} \mathrm{Ni}{ }^{+}$on RIS are shown in Figure 3. During both dual (micrographs in Figure $5 \mathrm{~b}$ ) and pre-implanted runs, no significant difference was observed in the growth of the irradiation-induced precipitate. An interesting feature in Figures $4 c$ and $5 b$ is the sink free 


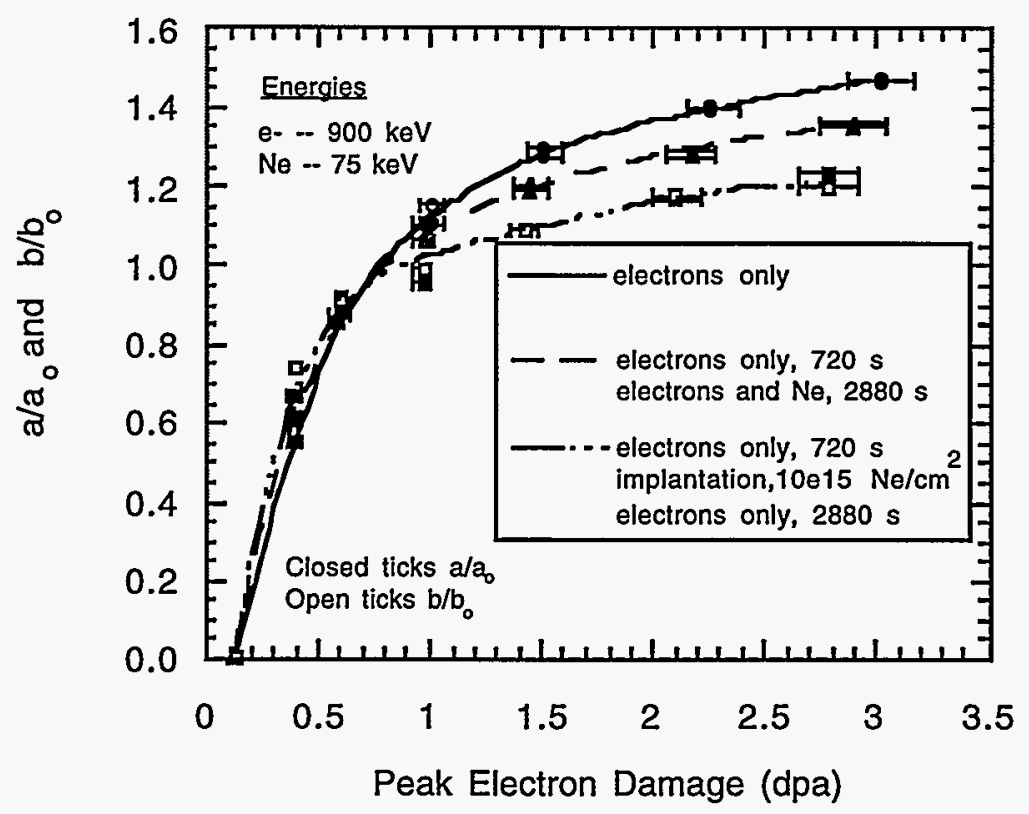

Figure 2. $\gamma^{\prime}-\mathrm{Ni}_{3} \mathrm{Al}$ growth curve for $900-\mathrm{keV}$ electron, dual $900-\mathrm{keV}$ electron $/ 75-\mathrm{keV} \mathrm{Ne}^{+}$ion, and preimplanted $75-\mathrm{keV} \mathrm{Ne}{ }^{+}$ion $/ 900-\mathrm{keV}$ electron irradiations at $550^{\circ} \mathrm{C}$. The $\mathrm{y}$-axis is the ratio of the precipitate zone size to the elliptical Gaussian beam dimensions, which allows for the normalization of irradiations with different electron beam conditions.

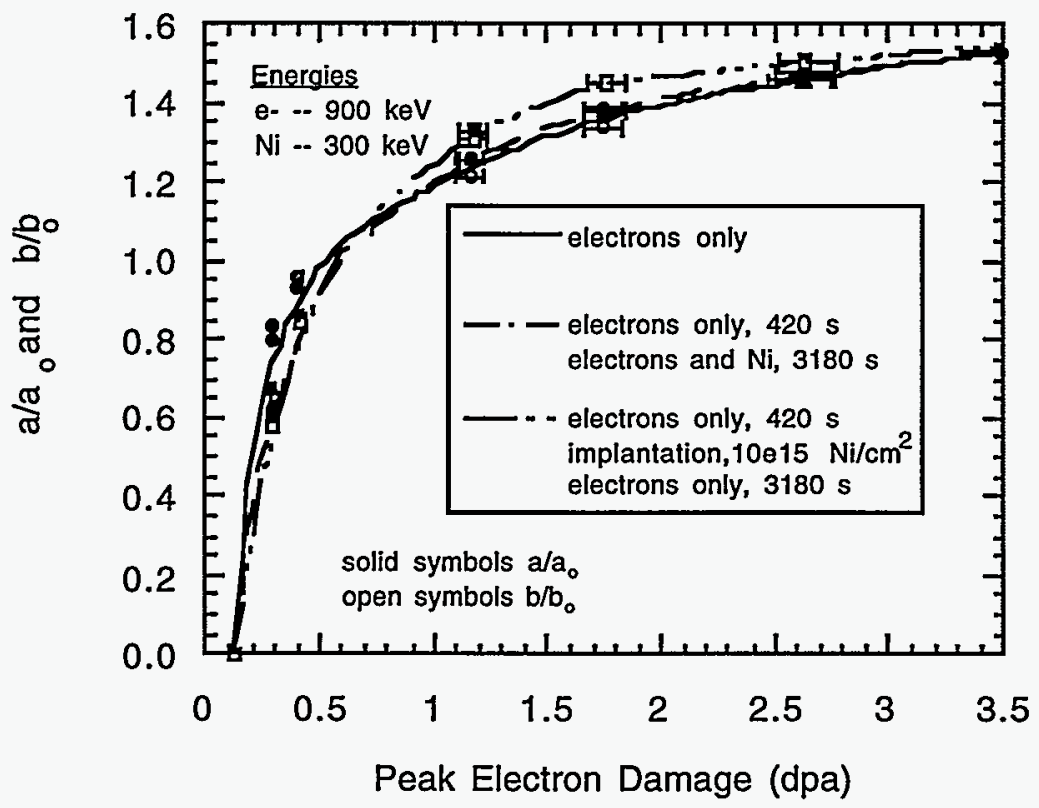

Figure 3. $\gamma^{\prime}-\mathrm{Ni}_{3} \mathrm{Al}$ growth curve for $900-\mathrm{keV}$ electron, dual $900-\mathrm{keV}$ electron $/ 300-\mathrm{keV} \mathrm{Ni}{ }^{+}$ion, and preimplanted $300-\mathrm{keV} \mathrm{Ni}{ }^{+}$ion $/ 900-\mathrm{keV}$ electron irradiations at $550^{\circ} \mathrm{C}$. The $\mathrm{y}$-axis is the ratio of the precipitate zone size to the elliptical Gaussian beam dimensions, which allows for the normalization of irradiations with different electron beam conditions. 
denuded zone surrounding the $\gamma^{\prime}$ precipitate zone. When $10^{15} \mathrm{ion} / \mathrm{cm}^{2}$ of $300-\mathrm{keV} \mathrm{Ni}{ }^{+}$were implanted, this denuded zone was replaced by a complex dislocation network.

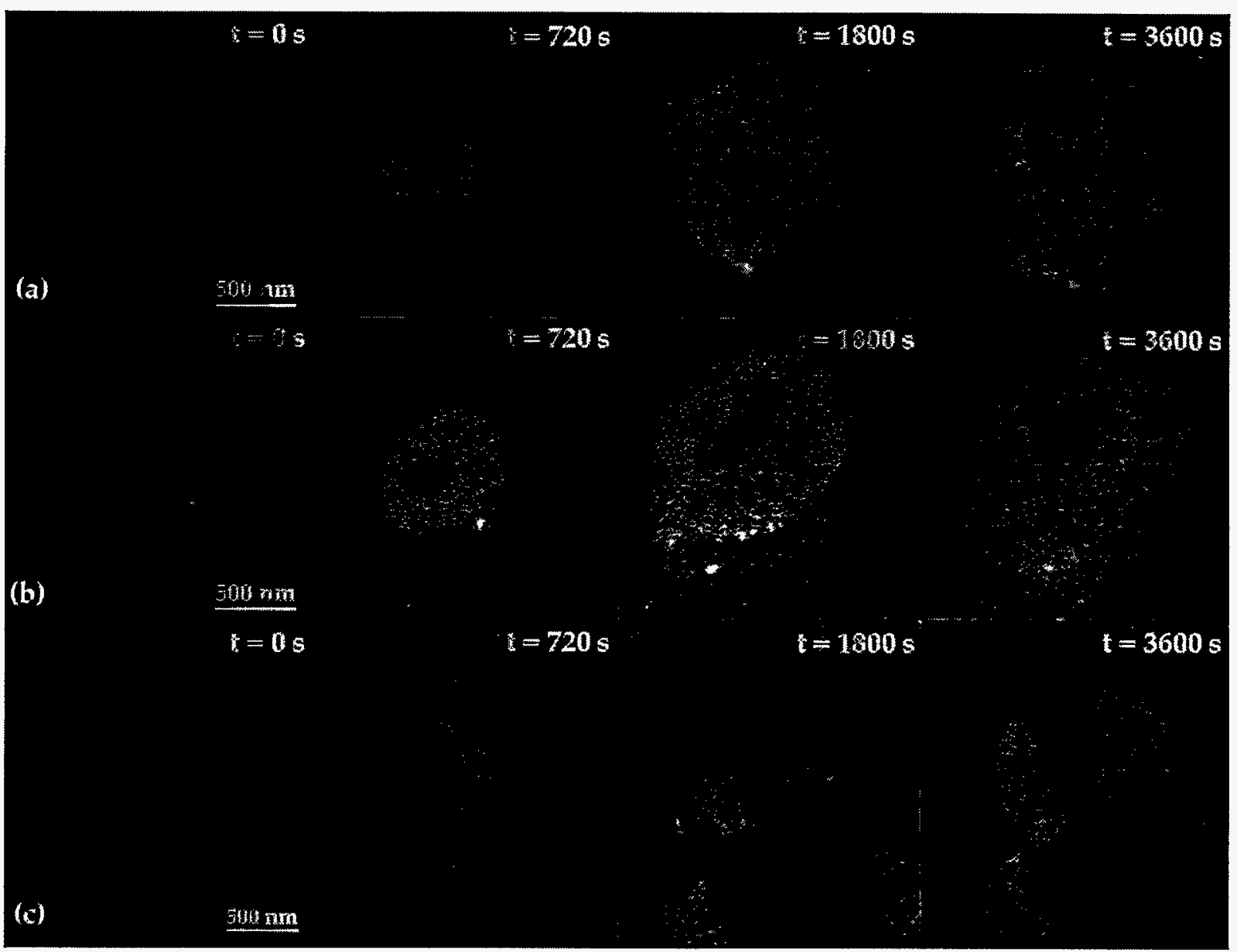

Figure 4. Precipitate growth as a function of time for (a) $900-\mathrm{keV}$ electron only for $36000 \mathrm{~s}(3.02$ $\left.\mathrm{dpa}, \mathrm{K}_{\text {peak }}=8.4 \times 10^{-4} \mathrm{dpa} / \mathrm{s}\right)$, (b) $900-\mathrm{keV}$ electron irradiation for $720 \mathrm{~s}(0.583 \mathrm{dpa})$ to grow the precipitate $\left(\mathrm{K}_{\text {peak }}=8.1 \times 10^{-4} \mathrm{dpa} / \mathrm{s}\right)$ followed by dual $900-\mathrm{keV}$ electron $/ 75-\mathrm{keV} \mathrm{Ne}$ irradiation for $2880 \mathrm{~s}(2.33 \mathrm{dpa})$, and (c) $900-\mathrm{keV}$ electrons only for $720 \mathrm{~s}(0.598 \mathrm{dpa})$ to grow the precipitate $\left(\mathrm{K}_{\text {peak }}\right.$ $\left.=8.3 \times 10^{-4} \mathrm{dpa} / \mathrm{s}\right)$, followed by $10^{15} \mathrm{Ne} / \mathrm{cm}^{2}$, followed by $900-\mathrm{keV}$ e lectrons $\left(\mathrm{K}_{\mathrm{peak}}=7.6 \times 10^{-4} \mathrm{dpa} / \mathrm{s}\right)$ for $2880 \mathrm{~s}(2.19 \mathrm{dpa})$. All irradiations were conducted at $550^{\circ} \mathrm{C}$ and listed damages are from electrons only.

\section{DISCUSSION}

Our results demonstrate that $75-\mathrm{keV} \mathrm{Ne}+$ irradiation has a suppressing effect on RIS and that $300-\mathrm{keV} \mathrm{Ni}+$ does not. In both cases, a sink structure develops: thus, this effect cannot be attributed to difference in the visible sink structure. 


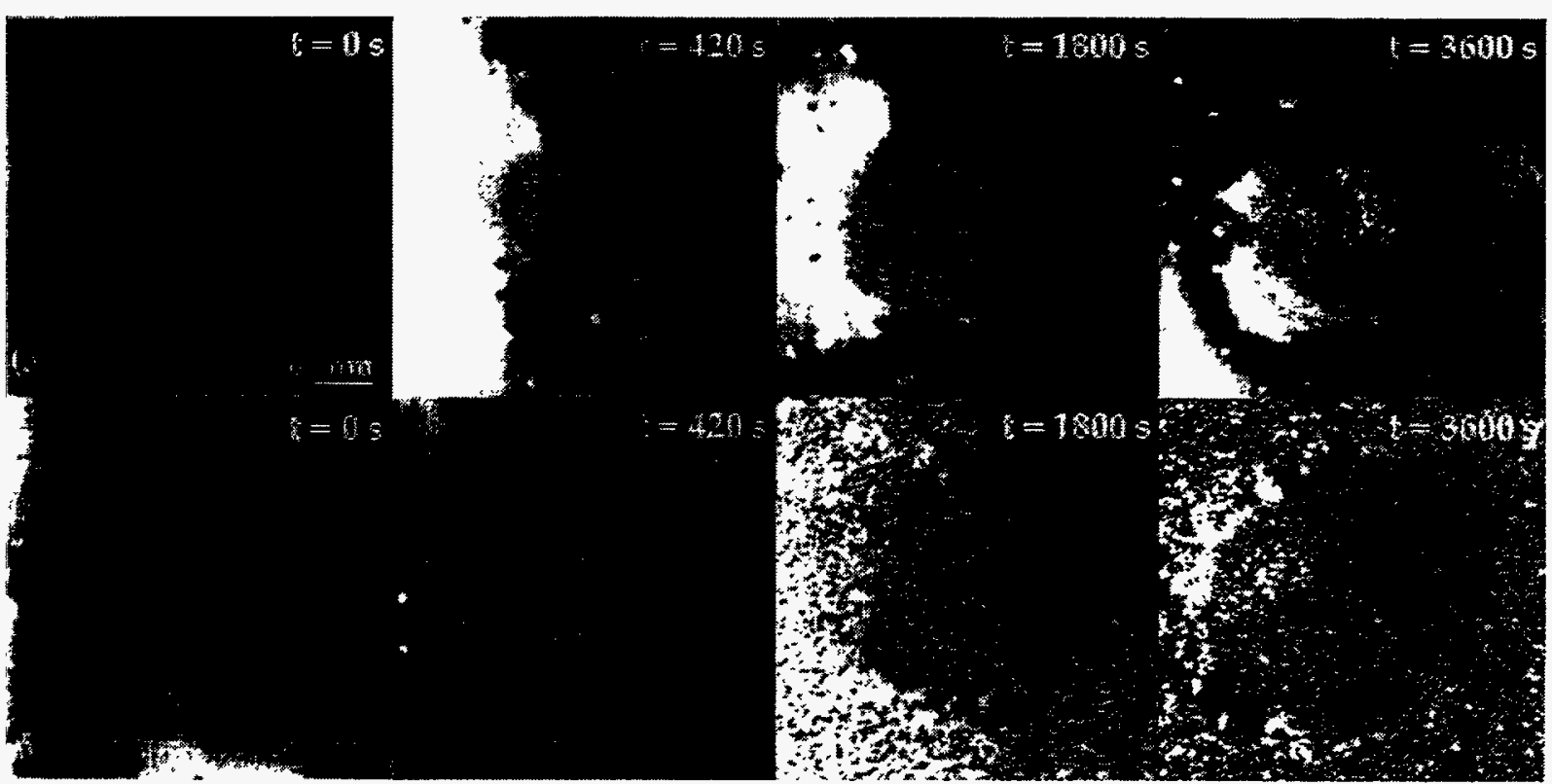

Figure 5. Precipitate growth as a function of time for (a) $900-\mathrm{keV}$ electron only irradiation for $3600 \mathrm{~s}$ (3.49 dpa, $\mathrm{K}_{\text {peak }}=9.7 \times 10^{-4} \mathrm{dpa} / \mathrm{s}$ ) and (b) $900-\mathrm{keV}$ electron irradiation for $420 \mathrm{~s}(0.407 \mathrm{dpa})$ to grow the precipitate $\left(K_{\text {peak }}=9.7 \times 10^{-4} \mathrm{dpa} / \mathrm{s}\right)$, followed by dual $900-\mathrm{keV}$ electron/300-keV $\mathrm{Ni}^{+}$dual irradiation for $3180 \mathrm{~s}(3.08 \mathrm{dpa})$. All irradiations were conducted at $550 \mathrm{oC}$ and listed damages are from electrons only.

Since RIS is cause by the defects which survive recombination, these results suggest that the presence of Ne causes a retardation in RIS by acting as a strong vacancy trapping site, hence enhancing recombination. It has been previously suggested that He clusters can act as defect trapping sites, enhancing recombination and reducing segregation in Ni-based alloys [10]. The $300-\mathrm{keV} \mathrm{Ni}^{+}$ion bombardment results in the present work contradict to some extent recent dual irradiation studies of RIS in $\mathrm{Cu}-1$ at.\%Au $[11,12]$. In that work, Iwase et. al $[11,12]$ concluded the cascade remnants of energetic displacement cascades were responsible for suppressing RIS. Further investigations are necessary to clearly determine the roles of cascade remnants and defect trapping in changing RIS behavior.

As mentioned in the previous section, a sink free denuded zone is present at the periphery of the central precipitate. At the present time, the reason for the formation of this denuded zone is unknown, and further studies are necessary to determine its nature.

\section{CONCLUSION}

In Ni-9at.\% Al irradiated with $900 \mathrm{keV}$ electrons at $550^{\circ} \mathrm{C}, \mathrm{Ne}$ implanted at $75-\mathrm{keV}$ had a suppressing effect on RIS of $\mathrm{Al}$, as demonstrated by the retarded growth of the $\gamma^{\prime}-\mathrm{Ni}_{3} \mathrm{Al}$ precipitate zone. $300-\mathrm{keV} \mathrm{Ni}^{+}$bombardment, however, had no effect on segregation kinetics both during dual electron-ion and pre-implantation (with $10^{15} \mathrm{Ni} / \mathrm{cm}^{2}$ ) electron runs. These results lead to the conclusion that Ne has a suppressing effect on RIS in Ni-9at\%Al. 


\section{ACKNOWLEDGMENTS}

The authors would like to thank L.E. Rehn for helpful discussions, and B. Kestel, E. Ryan, S. Ockers, and L. Funk for their experimental assistance.

\section{REFERENCES}

[1] P.R. Okamoto and L.E. Rehn, J. Nucl. Mater. 83, 2(1979).

[2] H. Wiedersich and N.Q. Lam, in: Phase Transformations during Irradiation, ed. F.V. Nolfi, Jr. (Applied Science Publishers, London, 1983) p. 1.

[3] R.A. Johnson and N.Q. Lam, Phys. Rev B13, 4364 (1976).

[4] P.R. Okamoto and H. Wiedersich, J. Nucl. Mater. 53, 336 (1974).

[5] N.Q. Lam and P.R. Okamoto, in Effect of Radiation on Materials: Twelfth International Symposium, ASTM STP 870, eds. F.A. Garner and J.S. Perrin (ASTM, Philadelphia 1985) p. 430.

[6] N.Q. Lam and P.R. Okamoto, J. Nucl. Mater. 133-134, 430 (1985).

[7] N.Q. Lam and P.R. Okamoto in Solute-Defect Interaction: Theory and Experiment, eds. S. Saimoto et al. (Pergamon Press, Toronto, 1986) p. 307.

[8] P.R. Okamoto and N.Q. Lam, Mat. Res. Soc. Symp. Proc. 41, 241 (1985): N.Q. Lam, P.R. Okamoto, and G.K. Leaf, Mat. Res. Soc. Symp. Proc. 74, 523 (1987).

[9] N.Q. Lam, G.K. Leaf, and M. Minkoff, J. Nucl. Mater. 118, 248 (1983).

[10] T. Ezawa, E. Wakai, T. Tanabe, and R. Oshima, J. Nucl. Mater 191-194, 1346 (1992).

[11] A. Iwase, L.E. Rehn, P.M. Baldo, and L. Funk, Appl. Phys. Lett. 67, 229 (1995).

[12] A. Iwase, L.E. Rehn, P.M. Baldo, P.R. Okamoto, H. Wiedersich, and L. Funk, Mat. Res. Soc. Symp. Proc. 316, 241 (1993) 